\title{
STRUCTURAL ANALYSES OF [Li SALT+TRIGLYME)] AND IONIC TRANSPORT IN Li-AIR BATTERY USING MOLECULAR DYNAMICS SIMULATION
}

\author{
MD. KHORSHED ALAM ${ }^{1}$, WATARU YAMAMOTO ${ }^{2}$ AND HIROMITSU TAKABA ${ }^{2}$ \\ ${ }^{1}$ Department of Physics, University of Barishal, Kornokathi, Barishal-8200, Bangladesh. \\ ${ }^{2}$ Department of Environmental Chemistry and Chemical Engineering, School of Advanced \\ Engineering, Kogakuin University, 2665-1 Nakano, Hachioji, Tokyo 192-0015, Japan.
}

*Corresponding authore-mail: khorshed_du@yahoo.com

Received on 18.04.2020, Revised received on 28.05.2020, Accepted for publication on 07.06.2020

DOI: https://doi.org/10.3329/bjphy.v27i1.49723

\begin{abstract}
In this work, molecular dynamics (MD) study of triglyme (G3) solution containing lithium bis (trifluoro methyl sulfonyl) amide (Li[TFSA]) were investigated using classical atomistic force fields. G3 is a typical solvent used in non-aqueous Li-air battery. It shows here coordination of $\mathrm{Li}+$ with $\mathrm{G} 3$ and [TFSA] does not significantly change with increasing the concentration of G3 but self-diffusion coefficient of all the ions increases with increasing G3 concentration. The density of [Li(G3)[TFSA] complex decreases with increasing G3 concentration which lead to accelerate diffusivity of ions.
\end{abstract}

Keywords: Li, TFSA, Molecular Dynamics, Li-air Battery.

\section{INTRODUCTION}

Growing demand for the large-scale energy storage solutions has stimulated the development of novel combinations of anodic and cathodic materials for advanced lithium-ion batteries (LIBs) and next generation batteries [1-3]. Ionic conductivity of electrolytes is especially important for electrochemical energy storage devices such as lithium batteries, because the power densities of the devices are greatly influenced by conductivity. In addition to mass transport in the electrolytes, charge transfer processes take place at the electrode/electrolyte interface. For the dissolution of a salt in solution to occur, the cation or anion should be solvated by the solvents. The solvent ion and ion-ion interactions have significant effects on the physicochemical properties of electrolyte solutions. Usually, lithium batteries use aprotic electrolyte solutions with $\mathrm{Li}^{+}$ion conductivity, and the $\mathrm{Li}^{+}$ion is involved in the electrochemical reactions of both the positive and negative electrodes [4-5]. During the charging of a lithium battery, $\mathrm{Li}^{+}$is released from the positive electrode material and $\mathrm{Li}^{+}$(or $\mathrm{Li}$ ) accumulates in the negative electrode material. During the discharging, reverse reactions take place at the positive and negative electrode. Room-temperature ionic liquids (RTILs), consisting of entirely cations and anions, are also important new electrolyte candidates. It may be applicable to fuel cells, [6-8] dye-sensitized solar cells, [9-11] and LIBs [12-16] to achieve high thermal stability in the electrochemical devices. For using RTILs as electrolytes for LIBs is to use them instead of organic solvents as a solvent for Li salts. Although these electrolytes are liquid at room temperature and have a high thermal stability, there are certain drawbacks, including low $\mathrm{Li}^{+}$ cation concentration, low $\mathrm{Li}^{+}$cation transference number, and concentration polarization during charge-discharge [17]. 
The conventional electrolyte of lithium-air batteries is composed of mixed organic solvents (cyclic carbonate and liner carbonate) and $\mathrm{LiPF}_{6}$ [4]. Linear carbonate solvents are extremely flammable, with flash points below room temperature, and $\mathrm{LiPF}_{6}$ decomposes in $\mathrm{HF}$ at temperature higher than $60^{\circ} \mathrm{C}$ [18]. So there is a thermal instability problem in Li-air battery at elevated temperatures. To maintain high degree of safety of lithium batteries, the development of thermally stable electrolytes is urgent.

Glymes are aprotic solvents, and they possess high thermal and chemical stability. Usually they are used as solvents in organic synthesis and glymes can easily dissolve alkali metal salts because glymes have high donor numbers. Oligo ether such as crown ethers, triglyme (G3) and tetraglyme (G4) form complexes with Li salts [19-21]. Some researchers have been reported about the crystallographic structures, thermal properties and ionic conductivity of solid-state glyme-Li salt complexes [22-24]. Among the series of glyme-Li salts complexes, [Li(G3) 1 TFSA] and [Li(G4) $)_{1}$ TFSA] remain in a liquid state at room temperature. Tamura et al. reported the physiochemical properties of molten complexes of glymes (G3, G4) with Li salts [25]. Hayamizu et al. reported RTILs of a quaternary ammonium cation having a DEME-TFSA-Li as an electrolyte and they elucidate dependence of the diffusion coefficient with respect to the change in the ratio of each substance [26]. In this paper, they elucidated that the ionic conductivity data shows that the charged ion migration is thermally activated easily compared to the migration of whole ions including paired ions, also with Li[TFSA] doping, the ionic conductivity and the ion diffusion decrease with increasing lithium salt concentration. Mandai et al. study the effect of ionic size on electrochemical and thermal stabilities using linear sweep voltammetry and thermogravimetry respectively, with the help of quantum mechanical calculations [27]. They found in the series of metal [TFSA] binary mixtures, certain complexes were formed depended on both glyme length, and metal ion and a trend in the complexation behavior of glymes with different metal [TFSA] were found. Tsuzuki et al. reported the chain length effects of glyme on the interactions between the [Li (glyme) ${ }^{+}$complex and [TFSA] ${ }^{-}$and diffusion of ions in the mixture [28]. There are many experimental reports about the physiochemical properties, ionic conductivities of glyme-salts complexes but as far we know there still there are very few studies about the dynamics properties of ions in the mixture complex.

In this study, we performed MD simulations in order to understand the dynamical characteristics of ions $\mathrm{Li}^{+}$, [TFSA] $]^{-}$and G3 in the [Li (G3) TFSA] complex for a wide range of G3 concentration. Radial distribution function from the simulations results revel the ionic interaction of $\mathrm{Li}^{+}$to the TFSA and G3 and investigate the overall structural properties of ionic liquid in this mixture complex. We also check the correlations of density of system, ionic transport properties of $\mathrm{Li}^{+}$, [TFSA] $]^{-}$and G3 in the [Li (G3) TFSA] with the concentration of the G3.

\section{METHOD}

Molecular dynamics simulations of glyme-Li salts complex were performed using the Forcite package [29-30]. Ball and stick model of G3 and TFSA are shown in Fig. 1. Initial structures and input files were constructed using Accelrys` Materials Studio package. Here Li[TFSA] used as a solute and G3 as solvent of this calculation system. There are four types of model prepared as [ $\left.\mathrm{Li}_{100}\right]\left[\mathrm{TFSA}_{100}\right],\left[\mathrm{Li}_{100}(\mathrm{G} 3)_{50}\right]\left[\mathrm{TFSA}_{100}\right],\left[\mathrm{Li}_{100}(\mathrm{G} 3)_{100}\right]\left[\mathrm{TFSA}_{100}\right],\left[\mathrm{Li}_{100}(\mathrm{G} 3)_{200}\right]\left[\mathrm{TFSA}_{100}\right]$ and we represent these as $\left[\mathrm{Li}_{100}\right]\left[\mathrm{TFSA}_{100}\right] \rightarrow[\mathrm{Li}(\mathrm{TFSA})], \quad\left[\mathrm{Li}_{100}(\mathrm{G} 3)_{50}\right]\left[\mathrm{TFSA}_{100}\right] \rightarrow\left[\mathrm{Li}(\mathrm{G} 3)_{0.5}(\mathrm{TFSA})\right]$, $\left.\left[\mathrm{Li}_{100}(\mathrm{G} 3)_{100}\right]\left[\mathrm{TFSA}_{100}\right] \rightarrow[\mathrm{Li}(\mathrm{G} 3)(\mathrm{TFSA})], \mathrm{Li}_{100}(\mathrm{G} 3)_{200}\right]\left[\mathrm{TFSA}_{100}\right] \rightarrow\left[\mathrm{Li}(\mathrm{G} 3)_{2}(\mathrm{TFSA})\right]$. Here we 
need to consider suitable force fields that are able to describe different solvents, solvent-molecule. Here we use COMPASS (condensed-phase optimized molecular potentials for atomistic simulation studies) [31] and Consistent Valence (CVFF) [32] force fields for designing to study ions that usually compose ionic liquids and other ionic compounds. The Ewald summation method was used to calculate long-range Coulomb interactions, with a cutoff distance is $12.5 \AA$. The MD method considered 3-dimensional periodic boundary conditions were used all spatial directions.

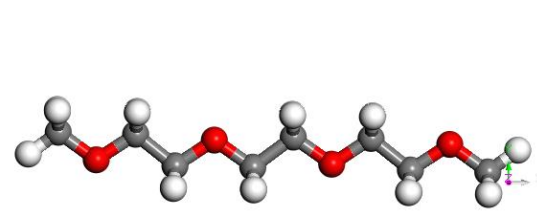

(a) G3

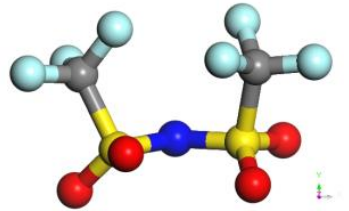

(b) TFSA

Fig. 1. Simulated molecules (a): triethylene glycol dimethyl ether (G3), (b) bis(trifluoro methyl sulfonyl) amide (TFSA). Oxygen atoms are in red, hydrogen in white, carbon in dark gray, fluorine in sky and nitrogen in blue.

MD simulations of the mixtures were carried out in the NPT ensemble. The non-bonded forces were truncated at $12.5 \AA$, while the Coulomb interactions were computed using Ewald method [33]. Constant-temperature and pressure were maintained by using the Nośe-Hoover chain thermostat [34] and the Andersen barostat [35].

Properties such as the radial distribution function (RDF) and mean squared displacement (MSD) were obtained with the NVE ensemble at a volume determined by the NPT simulation.

Radial distribution functions $\mathrm{g}_{\mathrm{AB}}(\mathrm{r})$ for various pairs of $\mathrm{A}$ and $\mathrm{B}$ type atoms are evaluated to characterize the structure of the pure liquids and their mixtures. $\mathrm{g}_{\mathrm{AB}}(\mathrm{r}) \mathrm{dr}$ is defined as the average number of atoms of type B in a spherical shell of radius $r$ and thickness $\mathrm{dr}$ around A-type atoms, normalized by the number of B atoms in the same shell, had the B atoms been distributed homogeneously in the system.

From result of MD calculation, we analyzed structure and self-diffusion coefficient $\mathrm{D}_{\mathrm{s}}$ of ionic liquid using RDF and MSD. We used equation (1) for RDF.

$$
\mathrm{gAB}(\mathrm{r})=\frac{n(r)}{4 \pi r^{2} d r \rho}
$$

Here $\mathrm{g}(\mathrm{r})$ is RDF, $\mathrm{r}$ is distance from original point, $\rho$ is average density, and $\mathrm{n}(\mathrm{r})$ shown molecular number presenting between small section dr. Also, we show here the calculation method of selfdiffusion coefficient $\mathrm{D}_{\mathrm{s}}$ from MSD using equation (2).

$$
D_{s}=\lim _{t \rightarrow \infty} \frac{\left|r_{i}(t)-r_{i}(0)\right|^{2}}{6 t}
$$

Here, $\mathrm{t}$ is the time moving molecule, $r_{i}(t)$ is molecular place of $\mathrm{t}$ second later, $r_{i}(0)$ is initial place of molecule.

\section{RESULTS AND DISCUSSION}

Fig.1 shows the structure of unit cell of (a) G3, (b) TFSA. Before perform MD simulation we checked Mulliken charge value of each atom using DFT calculation when we put each molecules 
on vacuum. The calculated Mulliken charge listed in Table 1. Here shows the charge value of oxygen and carbon atoms depends on its neighboring atoms of the complex. We prepared four types of model to perform MD simulation of this complex system as shown in Fig. 2. Initial cell size of each side was $70.0 \AA$. We have inserted molecules inside the box using adsorption tools. The each system contains 100 atoms Li ion, 100 TFSA but number of G3 varies for different model. We have compressed all the [Li(G3)TFSA] complex by geometry optimization with cell size relaxation as shown in Fig. 2. The results of equilibrium [Li(G3)TFSA] system for COMPASS force field shown in Table 2 of each system after optimization. We have also checked the cell size and density of the optimized system using cvff force field and compared with the COMPASS results. The calculated density of our [Li(G3)TFSA] equilibrium complex is $1.43 \mathrm{~g} / \mathrm{cm}^{3}$ for COMPASS force field which have good consistency with their experimental report [36].

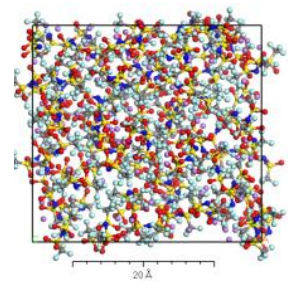

$[\mathrm{Li}][\mathrm{TFSA}]$

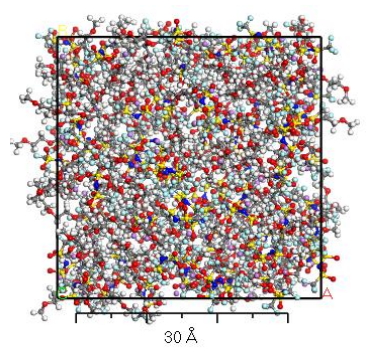

[Li (G3)][TFSA]

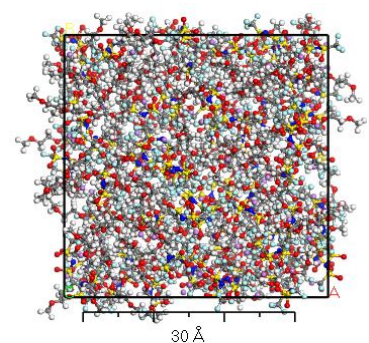

$\left[\mathrm{Li}(\mathrm{G} 3)_{0.5}\right][\mathrm{TFSA}]$

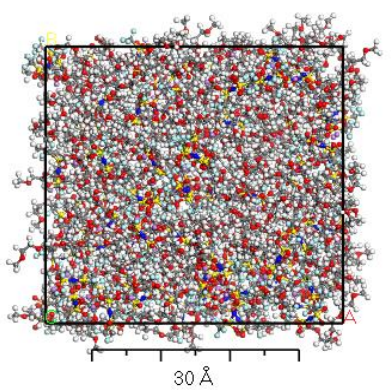

$\left[\mathrm{Li}(\mathrm{G} 3)_{2}\right][\mathrm{TFSA}]$

Fig. 2. Optimized equilibrium structure of [Li(G3)TFSA] for different concentration of G3.

Using optimized model, we performed dynamics calculation at each model as shown in Fig.3. MD simulations of the mixtures were carried out in the NPT ensemble. The dynamics calculation performed at $300 \mathrm{~K}$. From the MD simulation results we have considered only the final snapshots of the different mixture of [Li(G3)TFSA] from MD simulations at 2000 ps as shown in Fig. 3. The radial distribution functions of the ionic liquids were evaluated from the final snap of MD trajectories at $300 \mathrm{~K}$. The site-site intermolecular radial distribution functions in the [Li(G3)TFSA] 
complex as shown in Figs. 4, 5. The distribution functions between the $\mathrm{Li}^{+}$and oxygen atoms of $\mathrm{G} 3$ shown in Fig. 4 and the distribution functions between $\mathrm{Li}^{+}$and oxygen atoms of [TFSA] shown in Fig. 5.

Table 1: Charge analysis of each atom of G3, TFSA, Li and $\mathrm{O}_{2}$.

\begin{tabular}{llll}
\hline & Triglyme $(\mathrm{G} 3)$ & TFSA & $\mathrm{Li}^{+}$ \\
\hline $\mathrm{H}$ & 0.053 & & \\
$\mathrm{O}$ & -0.320 & -0.3045 & \\
$\mathrm{C}$ & $0.001\left(\mathrm{CH}_{3}\right), 0.054\left(\mathrm{CH}_{2}\right)$ & 0.6489 & \\
$\mathrm{~F}$ & & -0.182 & \\
$\mathrm{~S}$ & & 0.5061 & \\
$\mathrm{~N}$ & & -0.700 & \\
$\mathrm{Li}$ & & & 0.7 \\
\hline
\end{tabular}

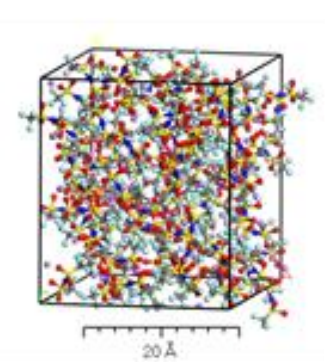

[Li] [TFSA]

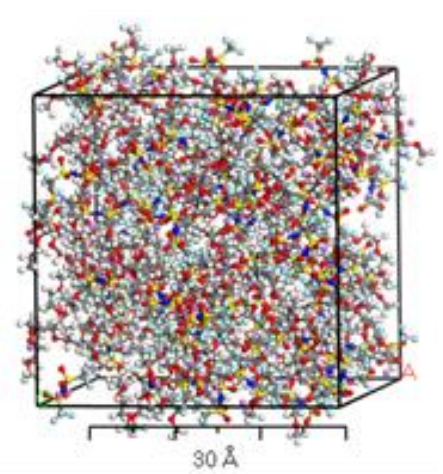

[Li (G3)][TFSA]

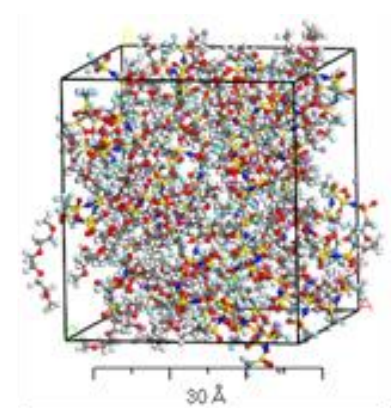

$\left[\mathrm{Li}(\mathrm{G} 3)_{0} \mathrm{~s}\right][\mathrm{TFSA}]$

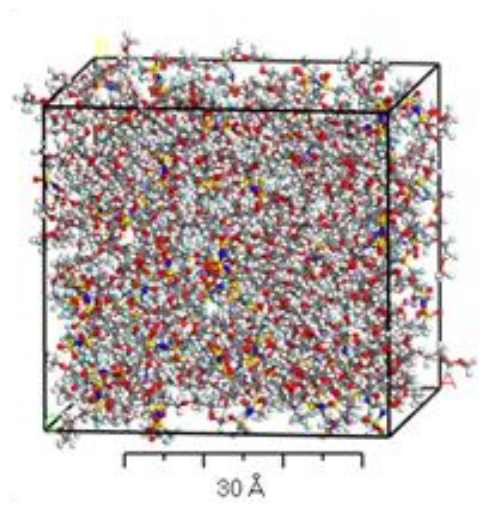

[ $\left.\mathrm{Li}(\mathrm{G} 3)_{2}\right][\mathrm{TFSA}]$

Fig. 3. Final snapshot taken from MD simulation of [Li(G3)TFSA] mixture for different concentration of G3.

In Fig. 4 shows radial distribution function of $\mathrm{Li}^{+}$and oxygen atoms of $\mathrm{G} 3$ has a sharp peak at around $2.0 \AA$. This radial distribution function analysis affirms the close contact between the $\mathrm{Li}^{+}$and oxygen of G3. Here we observed the effects of concentration of G3 on the radial distribution function is 
very small, peak distance does not change with the variation of G3 concentration but there is a little variation of peaks height with the variation of G3.

The radial distribution function of $\mathrm{Li}^{+}$and oxygen atoms of [TFSA] have a $1^{\text {st }}$ sharp peak around $2.0 \AA$, which indicates the coordination between $\mathrm{Li}^{+}$and oxygen atoms [TFSA]. The radial distribution functions were calculated by changing the concentration of G3 and also in the absence of G3. Although there is no significant effect of the concentration of G3 on the calculated radial distribution function of $\mathrm{Li}^{+}-(\mathrm{O})[\mathrm{G} 3]$ complex but we noticed effect on the radial distribution function of $\mathrm{Li}^{+}-[$TFSA] of the peak height with changing the concentration of G3 as shown in Fig.5. The radial distribution function of both the $\mathrm{Li}^{+}-\mathrm{O}[\mathrm{G} 3]$ and $\mathrm{Li}^{+}-\mathrm{O}[\mathrm{TFSA}]^{-}$pairs from our calculations, the peak distance, peak height and sharpness of the $1^{\text {st }}$ peak has conformity with the recent radial distribution function of the similar complex [29].

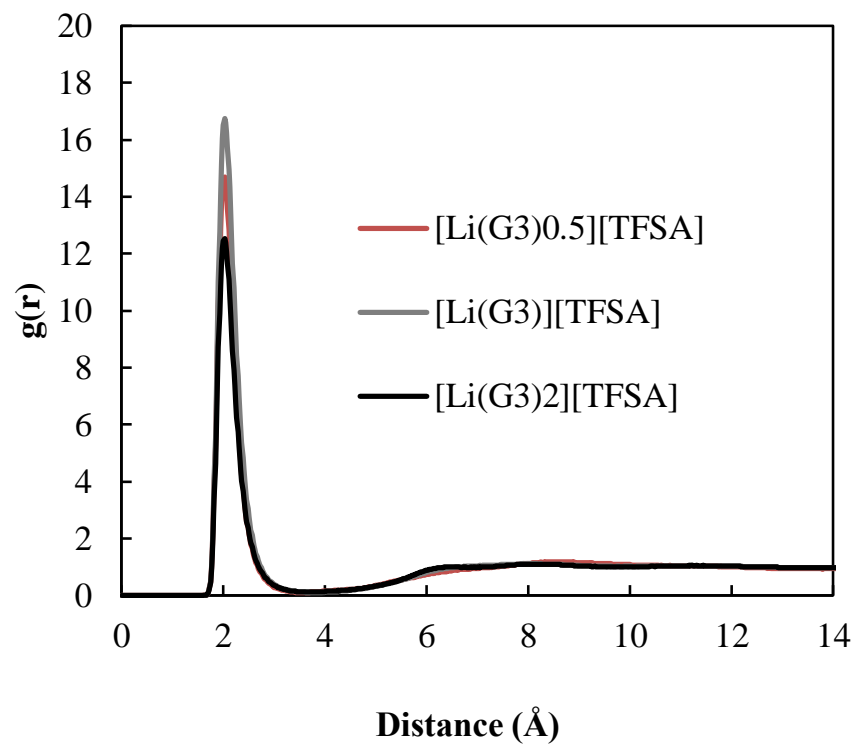

Fig. 4. $\mathrm{RDF}$ between $\mathrm{Li}^{+}$and $\mathrm{G} 3$ from the equilibrium structure after MD simulation.

We have also calculated the radial distribution function of both the $\mathrm{Li}^{+}-\mathrm{O}[\mathrm{G} 3]$ and $\mathrm{Li}^{+}-\mathrm{O}[\mathrm{TFSA}]^{-}$ pair using DFT method. The radial distribution function by DFT also shows that the sharp peak $\left(1^{\text {st }}\right.$ peak) located the distance around $2.0 \AA$, which is very similar to the radial distribution function of our MD calculations.

The peak distance from the radial distribution function of our MD simulation also indicates that $\mathrm{Li}^{+}$ is surrounded by oxygen atoms of $\mathrm{G} 3$ and distance between $\mathrm{Li}^{+}$and $\mathrm{O}$ of $\mathrm{G} 3$ is uniformed as we observed in Fig. 4. Here we have considered the strict structure of G3 so that the only $1^{\text {st }}$ peak is visible of radial distribution function for $\mathrm{Li}^{+}-\mathrm{O}[\mathrm{G} 3]$ and the $2^{\text {nd }}$ and $3^{\text {rd }}$ peaks is absent shown in Fig.4. To revel these phenomena we measured distance between $\mathrm{Li}^{+}$and $\mathrm{G} 3$ molecule from optimized [Li(G3)TFSA] complex from MD simulation and without using force field. The close distance between $\mathrm{Li}^{+}$and $\mathrm{O}$ of $\mathrm{G} 3$ are $1.844 \AA$, and $1.785 \AA$ for without force field and COMPASS 
force respectively. From this optimized structure, it shows that the distance between $\mathrm{Li}^{+}$and $\mathrm{O}$ of G3 has similarity for COMPASS and without force field (DFT).

In Fig. 5 shows radial distribution function focusing between $\mathrm{Li}^{+}$and (O)[TFSA] of [Li-TFSA], [Li(G3) ${ }_{0.5}$ TFSA], $\left[\mathrm{Li}(\mathrm{G} 3)_{1} \mathrm{TFSA}^{-} \text {, [Li(G3) }{ }_{2} \text { TFSA }\right]^{-}$complexes. Comparison with Fig. 4 and Fig.5 reveals that radial distribution function for $\mathrm{Li}^{+}-[\mathrm{TFSA}]^{-}$pair exhibited $2^{\text {nd }}$ and $3^{\text {rd }}$ peaks. On the other hand, there is no showing up $2^{\text {nd }}$ or $3^{\text {rd }}$ peaks for $\mathrm{Li}^{+}-\mathrm{O}[\mathrm{G} 3]$ pair in Fig. 4 . The reason for $2^{\text {nd }}$ and $3^{\text {rd }}$ peaks in $\mathrm{Li}^{+}-[\mathrm{TFSA}]^{-}$pair is that TFSA is not so strict so there may further close contact between atom pair that may lead $2^{\text {nd }}$ and $3^{\text {rd }}$ peaks.

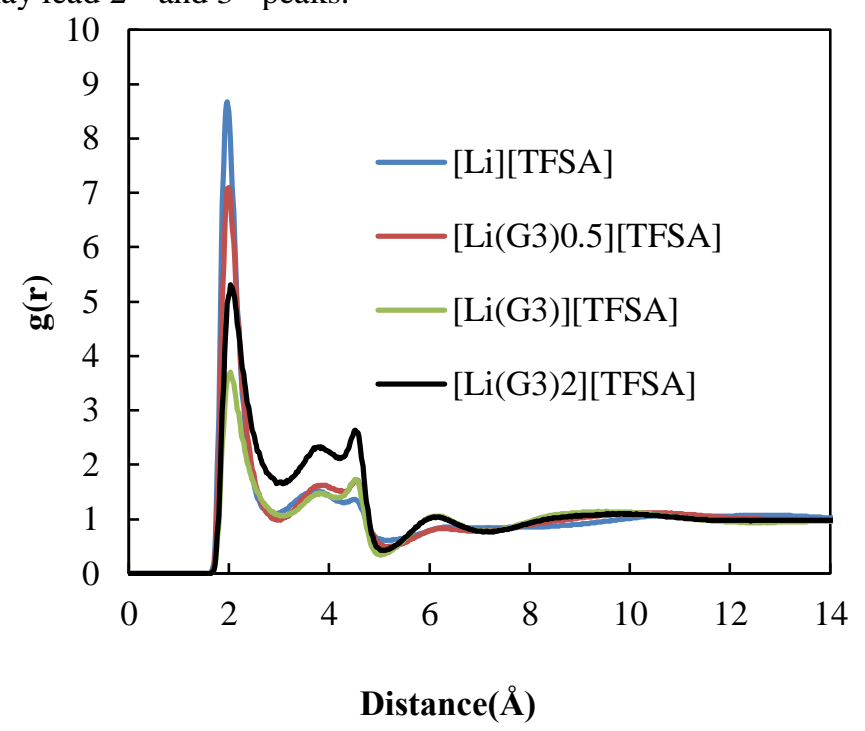

Fig. 5. RDF between $\mathrm{Li}^{+}$and TFSA from the equilibrium structure after MD simulation.

(a)

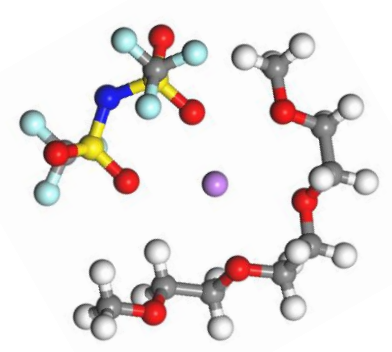

(b)

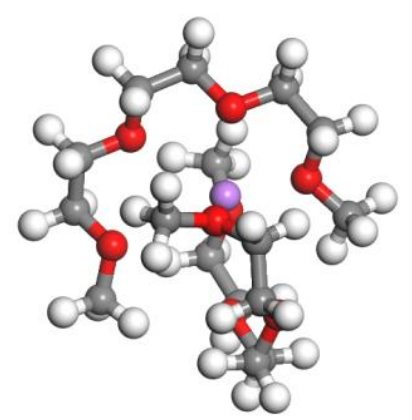

Fig. 6. Structural orientation of $[\mathrm{Li}(\mathrm{G} 3) \mathrm{TFSA}]$ for different conformation of G3 and TFSA molecules. 
The self-diffusion coefficient of $\mathrm{G} 3, \mathrm{Li}^{+}$and [TFSA] ${ }^{-}$in the mixture was measured from the MSDs of the ions and G3 as summarized in Table 3. The self-diffusion coefficient of $\mathrm{Li}^{+}$and $[\mathrm{TFSA}]^{-}$are $0.592 \times 10^{-12} \mathrm{~m}^{2} / \mathrm{s}$ and $0.534 \times 10^{-12} \mathrm{~m}^{2} / \mathrm{s}$ in the [Li] [TFSA] complex. The calculated self-diffusion coefficient of $\mathrm{Li}^{+}$, [TFSA] $]^{-}$, and G3 are $38.6 \times 10^{-12} \mathrm{~m}^{2} / \mathrm{s}$, and $41.9 \times 10^{-12} \mathrm{~m}^{2} / \mathrm{s}$, and $41.9 \times 10^{-12} \mathrm{~m}^{2} / \mathrm{s}$ respectively in the $\left[\mathrm{Li}(\mathrm{G} 3)_{2} \mathrm{TFSA}\right]$ complex. It shows the significant variation of the diffusivity of all the ions compare with the [Li][TFSA]. From the summarized results, in Table 3 exhibited that diffusion coefficient of all ions increased with increasing the concentration of G3 in the solutions. As we know $\mathrm{Li}^{+}$is coordinated with four oxygen atoms of $\mathrm{G} 3$ in the mixture complex. It indicates that effect of $\mathrm{G} 3$ on the self-diffusion coefficient $\mathrm{Li}^{+}$and [TFSA] $]^{-}$in the [Li(G3)TFSA] complex. If we compare the mobility of ions in the [Li(G3)TFSA] complex, it displayed that diffusivity of the G3 was fastest, $2^{\text {nd }}$ fastest was [TFSA] $]^{-}$and the $\mathrm{Li}^{+}$self-diffusion coefficient was the slowest. From the radial distribution function analysis, we saw [TFSA] is not so strict like G3 and nature of the $\mathrm{Li}^{+}-\mathrm{O}$ [TFSA] interaction is different than that of $\mathrm{Li}^{+}-\mathrm{O}(\mathrm{G} 3)$ which lead $\mathrm{G} 3$ is faster than [TFSA] ${ }^{-}$ and $\mathrm{Li}^{+}$. The order of the mobility of ions by our simulation results is comparable with previous experimental report [37]. We also observed that self-diffusion of all species in the [Li(G3)TFSA] complex is directly related to density of complex. Density of the complex decreases with increasing the G3 concentration (Table 2) therefore diffusion coefficient increased (Table 3).

Table 2: Calculated lattice parameter and density of the system for different concentration of G3.

\begin{tabular}{lccccc}
\hline \multicolumn{5}{c}{ lattice axis } & \multicolumn{3}{c}{} \\
\hline & $\mathrm{a}(\AA)$ & $\mathrm{b}(\AA)$ & $\mathrm{c}(\AA)$ & $\rho\left(\mathrm{g} / \mathrm{cm}^{3}\right)$ & Expt. [7] \\
\hline$[\mathrm{Li}][\mathrm{TFSA}]$ & 29.3 & 24.7 & 33.6 & 1.93 & \\
{$\left[\mathrm{Li}(\mathrm{G} 3)_{0.5}\right][$ TFSA $]$} & 33.9 & 35.4 & 32.8 & 1.59 & \\
{$[\mathrm{Li}(\mathrm{G} 3)][$ TFSA] } & 38.8 & 39.0 & 35.7 & 1.43 & 1.46 \\
{$\left[\mathrm{Li}(\mathrm{G} 3)_{2}\right][$ TFSA] } & 42.9 & 42.2 & 45.6 & 1.29 & 1.29 \\
\hline
\end{tabular}

Table 3: Calculated diffusion coefficients of Li ions and G3 in the [Li (G3)[TFSA] complex for different concentration of G3.

\begin{tabular}{lccc}
\hline & $\mathrm{D}_{\mathrm{Li}}\left(\times 10^{-12} \mathrm{~m}^{2} / \mathrm{s}\right)$ & $\mathrm{D}_{\mathrm{TFSA}}\left(\times 10^{-12} \mathrm{~m}^{2} / \mathrm{s}\right)$ & $\mathrm{D}_{\mathrm{G} 3}\left(\times 10^{-12} \mathrm{~m}^{2} / \mathrm{s}\right)$ \\
\hline$[\mathrm{Li}][\mathrm{TFSA}]$ & 0.592 & 0.534 & - \\
{$\left[\mathrm{Li}(\mathrm{G} 3)_{0.5}\right][$ TFSA $]$} & 1.18 & 2.35 & 2.46 \\
{$\left[\mathrm{Li}(\mathrm{G} 3)_{[T F S A}\right]$} & 10.7 & 12.4 & 17.2 \\
{$\left[\mathrm{Li}(\mathrm{G} 3)_{2}\right][$ TFSA $]$} & 38.6 & 41.9 & 83.5 \\
\hline
\end{tabular}

In Fig. 6 shows snap of MD simulation for (a) single $\mathrm{Li}^{+}$, TFSA and G3 (b) single $\mathrm{Li}^{+}$and two G3, to visualize the interactions of $\mathrm{Li}^{+}$with oxygen of G3 and TFSA. It's clearly shows that if there are both G3 and TFSA present in the system coordination of $\mathrm{Li}^{+}$with oxygen of G3 and TFSA are almost similar. On the other hand, when there is sufficient G3 molecule or absent of TFSA the coordination of $\mathrm{Li}^{+}-\mathrm{O}$ [TFSA] is different and $\mathrm{Li}^{+}$is closely surrounded by the terminal oxygen of G3. Radial distribution function, and diffusivity calculation of ions and G3 in the [Li(G3)TFSA] complex of our study reflected the effect of G3 concentration. 


\section{CONCLUSION}

This simulation study is to understand dynamical properties for low temperature of ionic liquid in a system consisting of Li[TFSA] and G3 covering a wide concentration range of G3. The simulation results indicated that concentration of G3 is the important for controlling factor of diffusivity of ions and G3. Radial distribution function indicate that the concentration of the G3 does not significantly affect coordination of $\mathrm{Li}^{+}-\mathrm{O}[\mathrm{G} 3]$ and $\mathrm{Li}^{+}-\mathrm{O}[\mathrm{TFSA}]$ but dilute the density of the complex which lead to increasing diffusivity of ions and G3. Different coordination nature of $\mathrm{Li}^{+}$with G3 and TSFA produced $2^{\text {nd }}$ and $3^{\text {rd }}$ peaks only for $\mathrm{Li}^{+}-\mathrm{O}$ [TFSA] pair, which indicated that TFSA is not so strict like as $\mathrm{G} 3$ and it is also one of the causes of faster diffusion of G3, compare to TFSA. Our simulation results also indicated that the diffusion coefficient order of $\mathrm{D}_{\mathrm{G} 3}>\mathrm{D}_{\mathrm{TFSA}}>\mathrm{D}_{\mathrm{Li}}$ in the [Li(G3)TFSA] complex and this sequence is comparable to experimental findings.

\section{ACKNOWLEDGEMENT}

This work was supported in part by the Kogakuin University, Japan by providing computational facilities.

\section{REFERENCES}

[1] V. Etacheri, R. Marom, R. Elazari, G. Salitra, D. Aurbach, Energy Environ. Sci., 4 (9), 3243, (2011).

[2] R. Santhanam, and B. Rambabu, J. Power Sources, 195 (17), 5442, (2010).

[3] P. G. Bruce, S. A. Freunberger, and L. J. Hardwick, Nature Materials, 11, 19, (2011).

[4] K. Xu, Chem. Rev., 104, 4303, (2004).

[5] K. Xu, Chem. Rev., 114, 11503, (2014).

[6] A. Noda, M. A. B. H. Susan, K. Kubo, S. Mitsushima, K. Hayamizu, and M. Watanabe, J. Phys. Chem. B, 107, 4024, (2003).

[7] H. Nakamoto, and M. Watanabe, Chem. Commun., 24, 2539, (2007).

[8] S.-Y. Lee, A. Ogawa, M. Kanno, H. Nakamoto, T. Yasuda, and M. Watanabe, J. Am. Chem. Soc., 132, 9764, (2010).

[9] W. Kubo, S. Kambe, S. Nakade, T. Kitamura, K. Hanabusa, Y. Wada, and S. Yanagida, J. Phys. Chem. B, 107, 4374, (2003).

[10] P. Wang, S. Zakeeruddin, J.-E. Moser, and M. Grätzel, J. Phys. Chem. B, 107, 13280, (2003).

[11] R. Kawano, and M. Watanabe, Chem. Commun., 3, 330, (2003).

[12] B. Garcia, S. Lavallèe, G. Perron, C. Michot, and M. Armand, Electrochim. Acta, 49, 4583, (2004).

[13] H. Matsumoto, H. Sakaebe and K. Tatsumi, J. Power Sources, 146, 45, (2005).

[14] H. Sakaebe, H. Matsumoto and K. Tatsumi, J. Power Sources, 146, 693, (2005).

[15] S. Seki, Y. Kobayashi, H. Miyashiro, Y. Ohno, Y. Mita, A. Usami, N. Terada, and M. Watanabe, Electrochem. Solid-State Lett., 8, A577, (2005).

[16] S. Seki, Y. Kobayashi, H. Miyashiro, Y. Ohno, A. Usami, Y. Mita, N. Kihira, M. Watanabe, and N. J. Terada, J. Phys. Chem. B, 110, 10228, (2006). 
[17] J.-W. Park, K. Yoshida, N. Tachikawa, K. Dokko, and M. Watanabe, J. Power Sources, 196, 2264, (2011).

[18] T. Welton, Chem. Rev., 99, 2071, (1999).

[19] R. E. A. Dilon, and D. F. Shriver, Chem. Mater., 11, 3296, (1999).

[20] W. A. Henderson, N. R. Brooks, W. W. Brennessel, and V. G. Jr. Young, Chem. Mat., 15, 4679, (2003).

[21] W. A. Henderson, N. R. Brooks, and V. G. Jr.Young, Chem. Mat., 15, 4685, (2003).

[22] W. A. Henderson, F. Makenna, M. A. Kahn, N. R. Brooks, V. G. Jr. Young, and R. Frech, Chem. Mat., 17, 2284, (2005).

[23] C. Zhang, D. Ainsworth, Y. G. Andreev, and P. G. Bruce, J. American Chem. Soc., 129, 8700, (2007).

[24] C. Zhang, Y. G. Andreev, and P. G. Bruce, Angewandte Chemie International Edition, 46, 2848, (2007).

[25] T. Tamura, K. Yoshida, T. Hachida, M. Tsuchiya, M. Nakamura, Y. Kazue, N. Tachikawa, K. Dokko, and M. Watanabe, Chem. Lett., 39, 753, (2010).

[26] T. Ogasawara, A. Débart, M. Holzapfel, P. Novák, and P. G. Bruce, J. American Chem. Soc., 128, 1390, (2006).

[27] T. Mandai, K. Yoshida, S. Tuzuki, R. Nozawa, H. Masu, K. Ueno, K. Dokko and M. Watanabe, J. Phys. Chem. B, 119, 1523, (2015).

[28] S. Tsuzuki, W. Shinoda, M. Matsugami, Y. Umebayashi, K. Ueno, T. Mandai, S. Seki, K. Dokkoe, and M. Watanabe, Phys. Chem. Chem. Phys., 17, 126, (2015).

[29] K. F. Khaled, and N. S. Abdel-Shafi, Int. J. Electrochem. Soc., 6, 4077, (2011).

[30] S. L. Mayo, B. D. Olafson, and W. A. Goddard, J. Phys. Chem., 94, 8897, (1990).

[31] H. Sun, J. Phys. Chem. B, 102, 7338, (1998).

[32] P. Dauber-Osguthorpe, V. A. Roberts, D. J. Osguthorpe, J. Wolff, M. Genest, and A. T. Hagler, Proteins: Structure, Function, and Genetics, 4, 31, (1988).

[33] M. P. Allen, and D. J. Tildesley, Clarendon Press, Oxford, U.K., 1987.

[34] G. J. Martyna, M. L. Klein, and M. Tuckerman, J. Chem. Phys., 97, 2635, (1992).

[35] H. C. Andersen, J. Chem. Phys., 72, 2384, (1980).

[36] K. Yoshida, M. Tsuchiya, N. Tachikawa, K. Dokko, and M. Watanabe, J. Phys. Chem. C, 115, 18384, (2011).

[37] K. Hayamizu, S. Tsuzuki, S. Seki, Y. Ohno, H. Miyashiro, and Y. Kobayashi, J. Phys. Chem. B, 112, 1189, (2008). 